\title{
RESEARCH PAPER \\ RUNNING DISTANCE EDUCATION IN STUDIO-BASED ART INSTITUTIONS: THE WAY FORWARD
}

\author{
G. Y. Annum \\ Department of Painting and Sculpture, Faculty of Art, KNUST, Kumasi
}

\begin{abstract}
Studio-based art institutions in Ghana have difficulty in running the system of distance education to increase student enrolment without compounding the problem of overcrowding. This is due to some major limitations with the predominant print technology for delivering instructional and learning materials to distance learners. Fortunately, advancement in technology in the area of video-conferencing, offer greater capabilities for providing more interactive distance learning experience, which studio-based institutions can exploit. However, high cost of employing videoconferencing technology becomes the main obstacle for its adoption in financially handicapped studio-based art institutions. In this paper therefore, the technological weaknesses of the print medium, vis-à-vis the capabilities of video-conferencing technology for running studio-based programmes in distance education has been examined. On the basis of the cost extremity of video-conferencing technology, the design-based and descriptive research methods have been employed to demonstrate the practicability of developing e-learning materials for running distance education effectively in studio-based art institutions at a lesser cost than through videoconferencing.
\end{abstract}

Keywords: Distance education, studio-based art, print medium, video-conferencing, technology

\section{INTRODUCTION}

Distance education is one of the most effective systems of education for increasing student enrolment with minimum enrolment challenges. The system particularly avails opportunities for workers to upgrade their academic credentials and improve their professional competence in their fields of specialisation. Many institutions in public universities in Ghana, for example, have adopted this system for this purpose.

Most institutions in the world today, especially in developing countries, that run distance education programmes relate more with theorybased courses whose learning materials are easy to package for both face-to-face and online accessibility to a wide variety of knowl- 


\section{Annum}

edge seekers. The print technology has been the predominant mode for delivering instructional and learning materials of such theory-based courses to learners. Since this technology has the limitation of the capacity to deliver practical skills effectively to the learner, it has been very difficult for studio-based art institutions to introduce and run programmes in distance education. It is unimaginable how audio-visuals of practical demonstrations of techniques and styles for executing art projects can be delivered through the print medium.

As noted by Stewart (2006), teaching practical art courses by distance learning has always been a challenge for both teachers and students. Text-based subject disciplines present fewer problems than art courses in the online realm because art courses require that students create and submit visual materials for appraisal and comment. Power (2001) declares that a course in Art would be difficult to offer in e-education. He does not see art colleges, as candidates for electronic education because for him, seeing and touching art are not the same as seeing a picture online.

The focus of this article is to discuss the possibility of developing an appropriate Interactive Learning Material Delivery Technology (ILMDT) that can be adopted for the running of this system in studio-based art institutions, not withstanding the practical oriented nature of their courses of study. It must be emphasised here that there exist modern advanced technologies with the capabilities of actualizing the introduction of the system of distance education in practical oriented institutions where the presence of the instructor is always necessary to demonstrate practical working procedures to students. Video-conferencing, which uses telecommunication channels to mediate the communication process, is one of such technologies suitable for running computer-based distance education most efficiently than the widely favoured print medium.

\section{PRINT MEDIUM}

Undoubtedly, ILMDT is the key component that drives distance education for effective communication and transfer of knowledge (NIL, 2000). Unfortunately, running distance education programmes in most developing countries have not advanced regarding technological developments of relevance to the system. For example, all the state owned universities in Ghana run their distance educational programmes predominantly on the print technology. The technology is one of the oldest and most widely used forms of educational resources. They include books, pamphlets, magazines, single sheets and even newspapers. This medium can easily be distinguished from other forms of media by the fact that it is composed of leaves or sheets of paper on which the information is documented before compiling them as reading materials, books or printed learning materials.

A major limitation that accompanies this technology is its inability to maximize access to other categories of information, especially in the case of audio-visual documents. It cannot present motion materials effectively; as a result, they cannot engage all the senses of the user for a total learning experience. However, it is a medium that can be combined effectively with other forms of media to form multimedia packages (Beswick, 1975).

It is as a result of the above limitation that the print medium cannot be the appropriate learning material delivery medium for running distance education in a studio-based art institution. Should there be the need to include audiovisuals of practical demonstrations in a course material, there is no way that they can be delivered in the print form. This implies that in countries where the print technology is the prime delivery medium for running distance education, programmes that will require the active use of the sense of hearing and seeing as in the case of studio-based art courses, may not survive. Video-conferencing technology in this case would be the most appropriate. 
VIDEO CONFERENCING TECHNOLOGY

McIsaac and Gunawardena (1996) once wrote that by the year 2000, many institutions would probably have adopted telecommunicationbased systems for the delivery of distance education to halt the over dominance of the print medium of the 1970's and the 1980's. True to this statement, today, more and more institutions that teach at a distance are moving toward multi-media systems integrating a combination of technologies both synchronous and asynchronous that meet learner needs. The most advanced being telecommunication-based medium with video-conferencing. The print medium however, has not been relegated to the doldrums, but continues to be used as supplementary in most telecommunications-based systems.

Video-conferencing technologies amalgamate television, video and sound technology as well as computers to enable instructors and students in different locations to see, hear and talk with one another. Video conferencing equipment can be set up on desks, with a camera and microphone to capture the person speaking and a monitor with a television-like screen and an inbuilt camera that allows the other person to see the person on the other line. In simple terms, the technology combines both telephone and television systems (Sawyer and Williams, 2005).

This technology, in the researcher's opinion could offer the best alternative means of teaching practical art at a distance because learners can always see instructors demonstrating procedures for practical execution. However, it could also pose financial and logistical challenges to institutions, which are financially handicapped. This is because as indicated by Sawyer and Williams (2005), it will require students owning personal computers equipped with in-built webcam and microphones and the establishment of learning centres equipped with video conferencing equipment. It will also necessitate consistent electricity power supply and a fast and reliable internet connectivity that runs on fibre-optic cable technology. This will mean a high cost of education, which will eventually defeat the essence for the introduction of distance education.

\section{THE WAY FORWARD}

If ILMDT is the key component that drives distance education for effective communication, then introducing it in studio art institutions, will be a daunting task to accomplish. This is because studio art courses always require practical demonstration of techniques and styles for executing projects. The presence of the instructor is always necessary in the teaching and learning environment. This obviously cannot be achieved through the print medium. Unless a virtual practical studio accompanies the delivery mode, it will be very difficult to employ the popular print medium as a means of transferring practical skills to distant learners. A consideration for Computer-based instructional and learning material delivery technology will offer the best alternative to the print technology.

An ILMDT meant for studio-based art institutions to run distance education should be such as to create a virtual art studio that can replicate a face-to-face environment. This is a major challenge that has to be surmounted if this system of education should be adopted. The technology must combine multimedia elements (sound, motion pictures, still pictures, quizzes and text documents) to help achieve learning objectives in practical dispensations.

\section{The nature of the delivery technology}

An experiment conducted by the researcher to develop a model instructional and learning material delivery technology yielded positive results. The uniqueness of this technology and its capabilities is what has been discussed below.

\section{Main interface}

The interface of a digital technology to deliver motion/still pictures and text documents should feature a Menu bar to drop-down Menus, Table 


\section{Annum}

of content panel to load all the topics for the study, and Text fields to open text documents (Fig. 1). The use of Tabs in designing the table of content panel will enable more topics to be added. The interface must also include a Control Panel that will present the end user with buttons to control the loading in and out of motion and still pictures.

As a learning material for a practical discipline, there is the need to replicate a practical studio environment, so that learners can experience hands-on demonstration of working techniques and styles from instructors virtually. In a faceto-face learning environment, students are able to ask questions and receive immediate res-

ponses from their instructors. This is not possible in distance learning because the learner and the teacher are in clear separation in space and time of the majority of teaching and learning activities (Keegan, 1990). Therefore, to enable some amount of interaction between the learner and the virtual instructor, the technology has to incorporate a display window that will project and playback accompanying still (Fig. 2) as well as motion pictures (Fig. 3) of all studio activities. This is discussed below.

\section{Motion and still pictures display window}

The motion-picture display window projects and plays back flash video files of practical working procedures that learners need most, in the absence of a physical instructor. It has its own control panel for the learner to pause, continue or restart the streaming simulation. It comes with a slider that makes it possible for the user to move the playhead to any location on the timeline of the clip when there is the need to repeat specific points.

On the still-picture display window, special buttons can be added as shown in Fig. 4 to open pages that provide descriptions to the character and function of tools and materials for practical work. It is also essential to add a button to playback voice recordings of the instructor to explain terminologies and issues that could possibly have generated discussions in a face-to-face

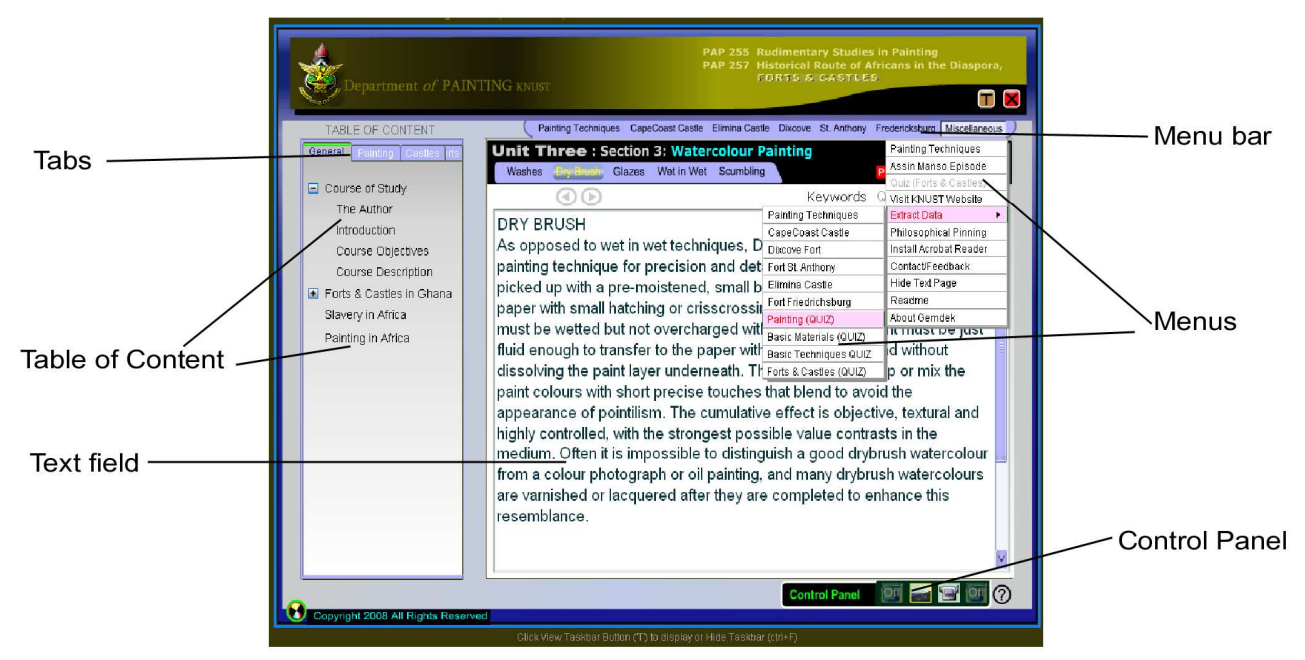

Fig. 1: Delivery technology (Main Interface) 


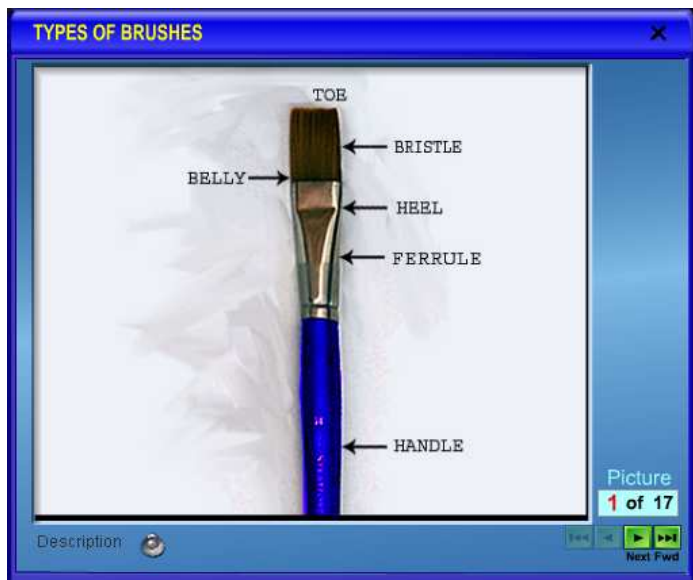

Fig. 2: Still-picture display window

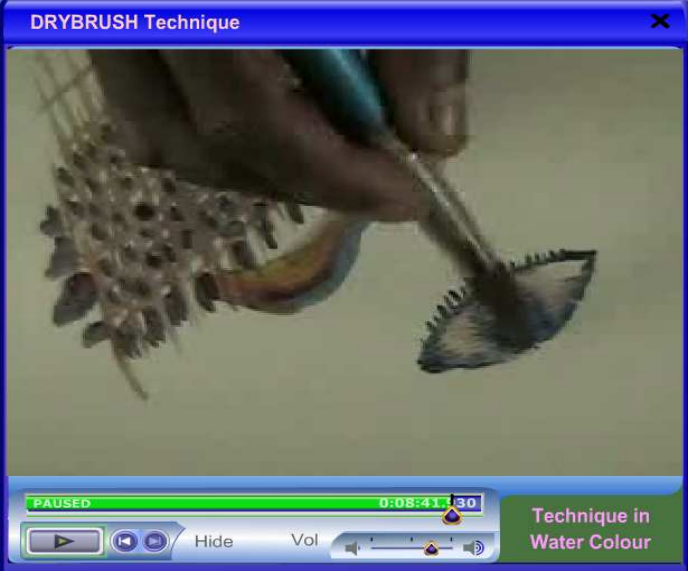

Fig. 3: Motion-picture display window

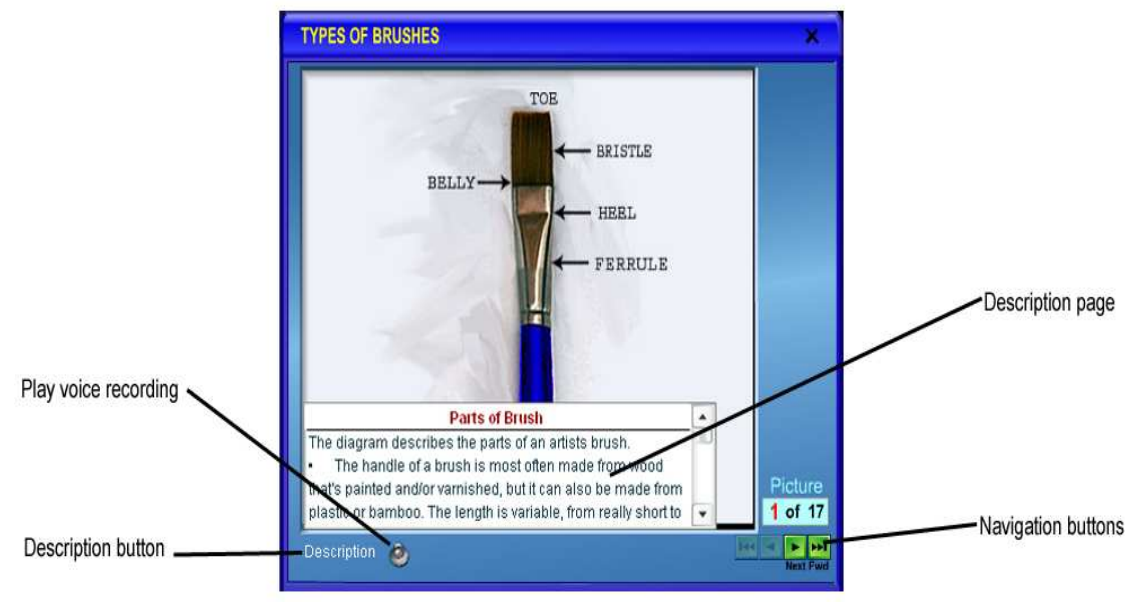

Fig. 4: Navigation buttons for reviewing still pictures

environment. A set of navigation buttons that will enable the learner to load in and navigate from one picture to another is also required for slide presentation. By these navigation buttons, the learner can skip familiar pictures and select new subjects for study.
Special features, which are very useful in electronic learning, include drop-down keyword box and explanation notes to the content (Fig. $5)$ as well as further reading reference pages (Fig. 6). These are text fields, which when added will provide additional information to 


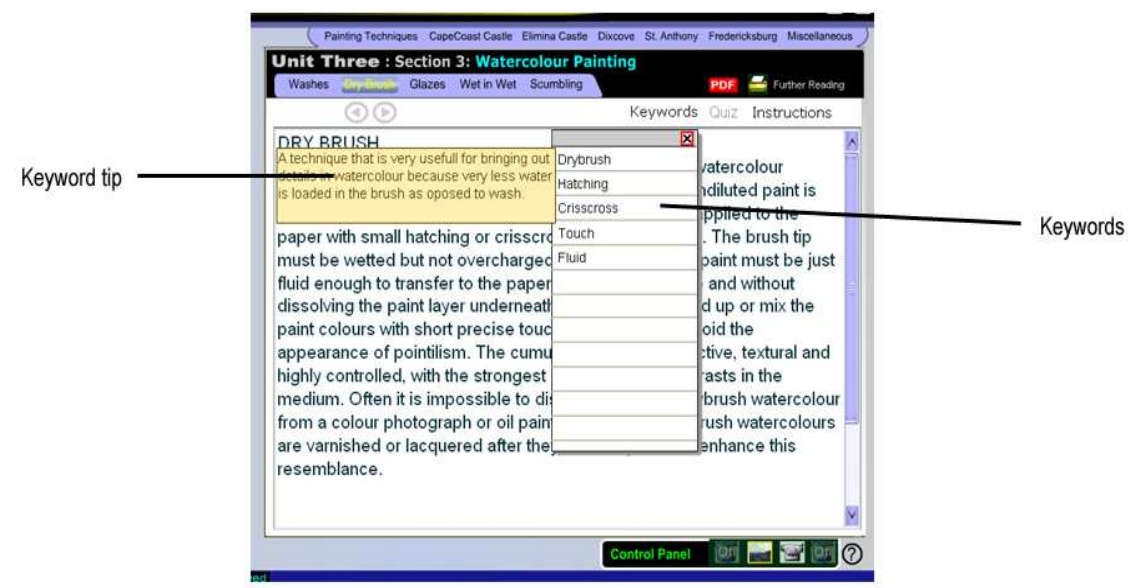

Fig. 5: Explanation notes on keywords

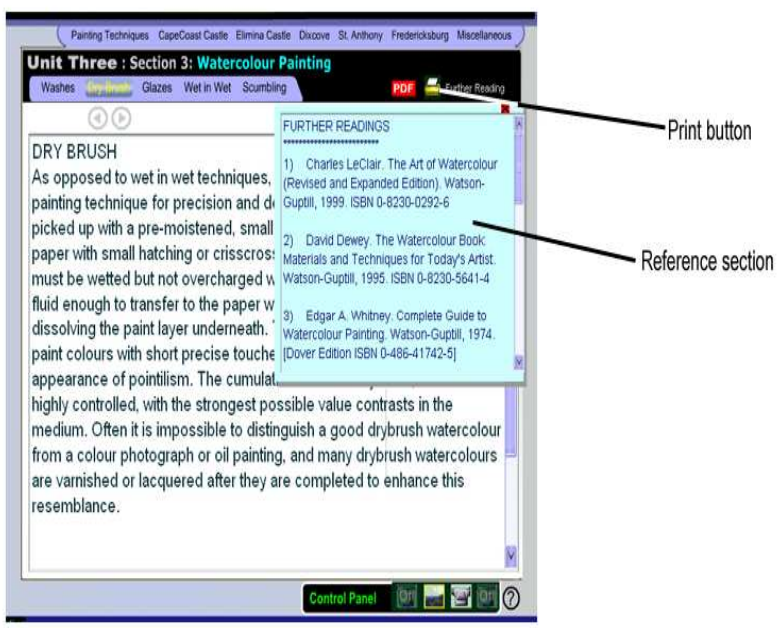

Fig. 6: Reference page for further readings

explain key terms and help them to assess more information from other sources of literature.

End-users of computer programmes often feel exhausted from prolonged sitting behind the computer screen, reading scrolls of pages. Most often preference is given to hardcopies of notes rather than softcopies. It must therefore be possible for the distance learner to print copies of the 
text documents provided in the e-content material. This means a print button must accompany each text document displayed (Fig. 6). It is advisable to format printable materials in Portable Document Format (PDF files) to render them non-editable.

This technology is ideal for delivery as an optical disc-based multimedia material due to the huge sizes of the video files that are incorporated which will be a challenge for domain service providers to contain. Otherwise, it can also be delivered through the internet infrastructure.

\section{EXPERIMENTING WITH THE TECH- NOLOGY}

Since there is currently no art institution in Ghana running programmes through distance learning, it was necessary to test the viability of this delivery technology with both practical and theory courses. The practical focused on watercolour painting technique whilst the theory focused on Thesis Writing skills. A class of 62 third year Painting and Sculpture students in the Department of Painting and Sculpture at KNUST all of whom were non-resident constituted the subject of the study. The learning materials were delivered on both optical disc (DVD) and through KNUST e-learning site (http://web.knust.edu.gh/elearning/course/ view.php?id=24) hence, students at any point in time could interact with the learning materials even in the absence of the instructor.

The optical disc-based material was developed with 'Adobe Flash'. It incorporated the major multimedia elements of text documents, graphics and most especially, audio-visual materials, to demonstrate and explain watercolour techniques in painting. This was developed with standalone functionality at a production cost of only five cedis (Ghф5.00) per DVD. The online material, which was on thesis writing skills, was developed with 'Microsoft Word'. It showed related links to other useful websites to enable students interact with other useful information of content materials. This was a strategy to create learner-centred learning environment and for students to meet their learning needs through reading, observation and hearing of voice recordings. The essence of this, was to facilitate electronic learning for the first time in the department, and to ensure that without the physical presence of the course instructor, students could meaningfully understand the lessons of the course.

The issue of paying dearly for missing lectures no longer bordered students because lecture notes and ancillary materials were always available in the virtual classroom to be accessed at any time. Students' attendance in the virtual classroom could also be monitored. This is because KNUST e-learning site is designed on Moodle platform, which provides additional functionalities for creating forums, chats and security settings to control student enrolment and interaction with learning material. The technology was beneficial to the students all of whom resided off-campus, since they only had to meet for a face-to-face session with the instructor, once every month.

\section{Ascertaining students learning experience}

To ascertain the popularity of this technology and its impact on the students learning experiences, a questionnaire was administered to each of the 62 students at the close of the second semester of 2011/2012 academic year, with the motivation to submit unequivocal responses to help evaluate the system and the learning medium. The result was to establish the practicability of the technology to meet the learning needs of the students, confirm its acceptability and to endorse it as an ILMDT tool, to enable studio-based art institutions to run programmes through the system of distance education.

The questionnaire was in two parts. The first part sought for brief personal information about the respondents, excluding their names whilst the second part, comprised of ten questions (five closed and five opened), to elicit their reaction to the idea of running those courses through e-learning and the impact of their learning experience. All the questionnaires ad- 


\section{Annum}

ministered were retrieved.

\section{RESULTS AND DISCUSSION}

Students responses to the open-ended questions emphatically confirmed 'thesis writing' as the only course in the department that was delivered by electronic mode through the online virtual system, an indication that the system was yet to be embraced in the department. Again, the results registered a hundred percent $(100 \%)$ endorsement for the introduction of the system of e-learning in the department even though bandwidth constraints pose a critical hindrance to its implementation. Table 1 and Figs. 7 - 10 indicate the distribution of the responses of the students to the questions posed.

The area of much concern from the students' reaction, which poses a big challenge to the adoption of this system in the department, is the rate of accessibility of learning materials over the internet. More than half $(51 \%)$ of the class of 62 students indicated that they could access the materials but with difficulty whilst $47 \%$ did not encounter difficulties in accessing learning materials (Fig. 8). This possibly explains why only $24 \%$ had very exciting learning experience through this system as against $63 \%$ with exciting experience and $13 \%$ with less exciting experience (Fig. 10). It is also an indication that the network system in terms of bandwidth space in any institution proposing for the adoption of this system has to be broad enough to enhance smooth flow of heavy volumes of electronic information if all students are to derive full benefits of the system of e-learning.

Regarding the level of interactivity of the learning material, which is vital to e-learning, 92\% indicated that it was interactive as against $8 \%$ who said it was not (Fig. 7). E-learning material developers wish their beneficiaries to enjoy full interactivity of their products. Any section of the learning population who reports otherwise should be a matter of concern. By the students' assessment of the learning material in terms of

Table 1: Frequencies of responses from students

\begin{tabular}{lccc}
\hline \multicolumn{1}{c}{ Questions } & Option of responses & Freq. of responses \\
\hline & & No & \% \\
Are the e-learning materials interactive? & Yes & 57 & 92 \\
& No & 5 & 8 \\
What is the degree of accessibility of the learn- & Easily accessible & 29 & 47 \\
ing material over the internet? & Accessible with difficulty & 32 & 51 \\
& Not accessible & 1 & 2 \\
What is your candid assessment of the nature of & Excellent & 7 & 11 \\
the learning material in terms of content, and & Very good & 42 & 68 \\
interactivity? & Good & 12 & 19 \\
& Bad & 1 & 2 \\
What has your learning experience been like? & Very exciting & 15 & 24 \\
& Exciting & 39 & 63 \\
Will you recommend the adoption of this & Less exciting & 8 & 13 \\
system for your department? & Unexciting & 0 & 0 \\
\hline
\end{tabular}




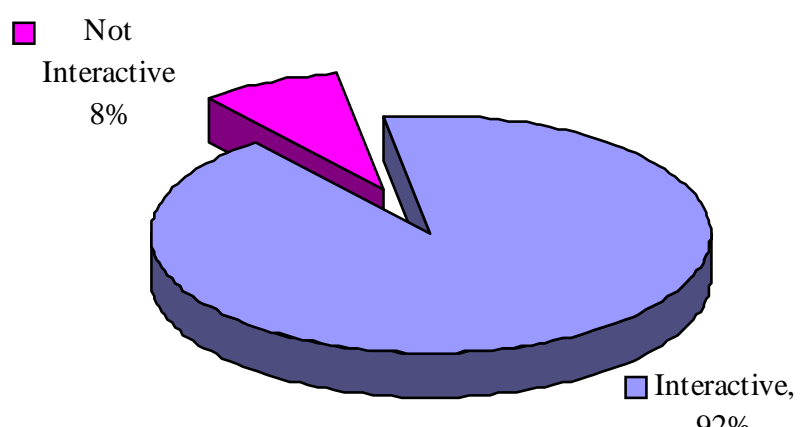

$92 \%$

Fig. 7: Interactivity of the e-learning materials

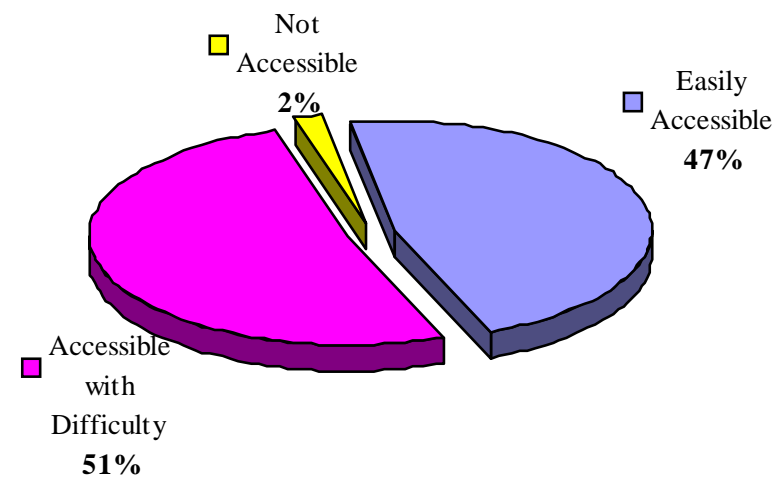

Fig. 8: Accessibility of the learning material over the internet

content and interactivity, $68 \%$ said it was very good as against $2 \%$ who found the material to be bad. Thus, $11 \%$ valued it as excellent whilst $19 \%$ deemed it to be good (Fig. 9). The entire class of 62 students recommended the adoption of this system in the department. This was a sign that the students who are the focus of education would embrace the system.

\section{CONCLUSION}

Although there are appropriate technologies like video-conferencing that can facilitate the 


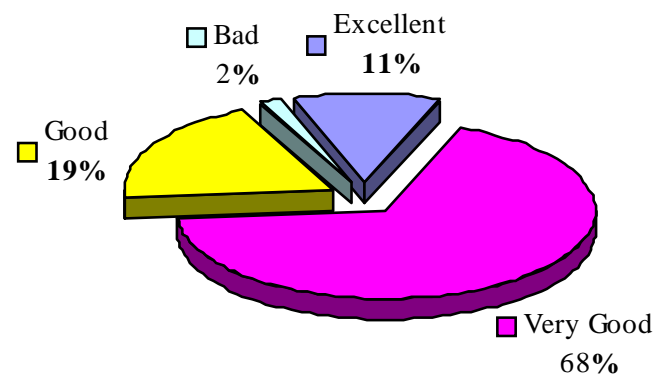

Fig. 9: Students assessment of the nature of the learning material in terms of content and interactivity

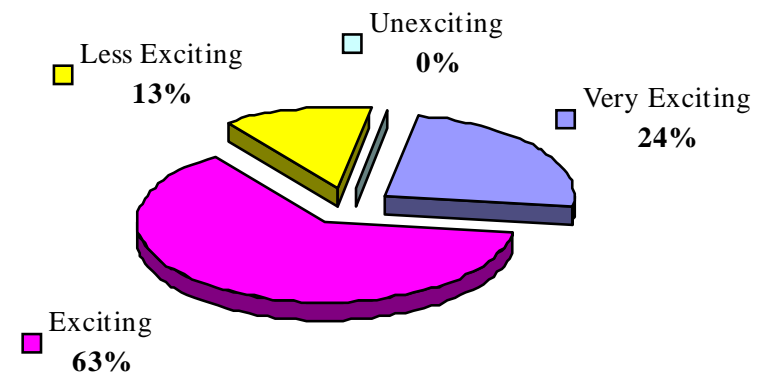

Fig. 10: Students' learning experience with the software

running of programmes in distance education for practically oriented tertiary institutions, it will be very challenging for art institutions in Ghana to run this system of education. Financial capacity is the obvious difficulty that could threaten its success. The need for developing the technological acumen to appropriate deliv- ery technologies that incorporate graphics, sound, video and text documents in the development of course materials for distance learners should be embraced.

Although similar technologies have been employed in specialised fields of study as in the 
Running studio-based programmes in distance education...

case of interactive software, adoption of any of these in distance education to resolve the problem of overcrowding in any studio-oriented art institution is yet to be experimented. The researcher in this article has demonstrated that it is possible to develop a computer-based educational technology that can help studio art institutions to also introduce the system of distance education in their institutions as a novelty worthy of adoption by other practically oriented institutions.

\section{RECOMMENDATIONS}

It is however worth noting that, the success of running this system of education in studiobased art institutions will immensely depend on a number of factors, including most importantly:

Organisation of special training workshops to equip instructors with the expertise of writing course materials. This is because any vibrant e-content development unit will require the collaboration of the capabilities of distance educational course writers and e-learning material developers. It does not take any one at all to write a course material. It requires a special skill that has to be acquired through training.

Preparedness to establish ICT centres nationwide which will be the access points for students who cannot own personal computers, to have easy access to such devices where they can interact with disc-based learning materials and also be able to reach their examiners online.

The use of appropriate bandwidth space to network computers for e-learning to facilitate easy accessibility of all manner of learning elements.

\section{REFERENCES}

Beswick, N. (1975). Organizing Resources: Six Case Studies, The Final_Report of the Schools Council Research Centre Project, London: Heinemann.

Keegan, D. (1990). Foundations of Distance Education, London: Routledge.

McIsaac, M. S. and Gunawardena, C. N. (1996). Distance Education. In D.H. Jonassen, ed. Handbook of research for educational communications and technology: a project of the Association for Educational Communications and Technology. 403-437. New York: Simon \& Schuster Macmillan. (http://seamonkey.ed.asu.edu/ mcisaac/ dechapter/tech1.htm). (Accessed on July 2, 2010).

'NIL' (2000). "How states are implementing distance education for adult learners", National Institute for Literacy, (http:// w d r.dole ta.gov/re s e a r c h/pdf/ nifldistance.pdf). (Accessed on March 21, 2009).

Power, C. (2001). "Cyberschools take off as Colleges go Internet route", Irish Times of April 13.

Sawyer, S. C. and Williams, B. K. (2005). Using Information Technology $\left(6^{\text {th }} \mathrm{Ed}\right)$, McGraw Hill Technology Education.

Stewart, M. (2006). Teaching Art at a Distance, United Kingdom: Association for Computing Machinery, Inc. (http://www.elearnmag.org/

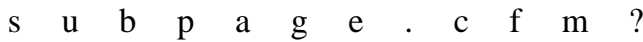
Section $=$ casestudies \& article $=39-1$ ) (Accessed on September 3, 2009). 